\title{
The demand for energy in the large- scale manufacturing sector of Pakistan
}

\author{
Fakhre Mahmud and Salim Chishti
}

\begin{abstract}
The extent of interfuel substitution, as well as substitution between energy and non-energy inputs, in the large-scale manufacturing sector of Pakistan has been examined. The model has been estimated in two stages. In the first stage input demand for various energy components is estimated and hence an aggregate Divisia index is constructed. In the second stage this index is used as an instrument to estimate aggregate input demand for capital, labour and energy along with their price and substitution elasticities. It seems that there is little interfuel substitution. The results also show that energy and labour are substitutes while energy and capital are complement.
\end{abstract}

Keywords: Energy: Manufacturing; Pakistan

Pakistan's large-scale manufacturing sector has been growing at over $7 \%$ per annum. The sector consumes about $35 \%$ of total commercial energy, demand for which is growing at over 6\% per annum. Energy has been a major constraint on the growth of the sector (Pasha et al [10]). Pakistan is a net oil-importing country, spending about $22 \%$ of its export earnings. While serious strides are underway to cope with the energy constraint from the supply side, in the past efforts have been made to adopt demand management policies to make interfuel, as well as fuel and non-fuel substitutions. However, there are few analytical studies to evaluate the impact of demand management policies. The purpose of this paper is to study the substitution between different carriers of energy as well as between energy and non-energy inputs in the manufacturing sector of Pakistan.

\section{The model and data}

Following Fuss [4] the model is estimated in two stages. In the first stage input demands for various energy

Fakhre Mahmud is Visiting Professor, Faculty of Economics and Administration, Bilkent University. Maltepe Ankara, Turkey and Salim Chishti is Senior Research Economist at the Applied Economics Research Centre, University of Karachi, PO Box 8403, Karachi 75270, Pakistan.

Final manuscript received 19 December 1989 components are estimated and hence an aggregate price Divisia index for energy is developed. In the second stage this index is used as an instrument variable to estimate aggregate input demand for capital, labour and energy along with their price and substitution elasticities.

It has been assumed that the aggregate production process can be represented by a translog production process with three inputs, namely capital, labour and energy which is weakly separable in energy. Invoking duality relations in production and cost, this can be equivalently represented by a translog cost function which is also weakly separable and can be written as:

$$
\begin{aligned}
\ln C= & \ln \alpha_{o}+\sum \alpha_{i} \ln P_{i}+\alpha_{Q} \ln Q+\frac{1}{2} \sum_{i} \sum_{j} v_{i j} \ln P_{i} \cdot \ln P_{j} \\
& +\sum_{v i Q} \ln _{Q} \cdot \ln P_{i}+\frac{1}{2} v Q Q(\ln Q)^{2} \\
& i j=E \text { (energy, } N \text { (labour), } K \text { (capital) }
\end{aligned}
$$

where $P_{E}$ is an aggregate price index of all energy components. Partially differentiating Equation (1), invoking Shephard's lemma and imposing homogeneity, adding up and symmetry restrictions yields the following input demand equations:

$$
\begin{gathered}
\mathrm{S}_{\mathrm{i}}=\alpha_{i}+\sum_{j} \tau_{i j} \ln P_{j}+\tau_{i Q} \ln Q \\
i, j=E, N, K
\end{gathered}
$$


Corresponding to Equation (2) the Allen-Uzawa partial substitution elasticities are given by:

$$
\begin{gathered}
\sigma_{i j}=\begin{array}{l}
\tau_{i j}+S_{i} S_{j} \\
\mathrm{~S}_{i} \mathrm{~S}_{j}
\end{array} i, j=E, N, K ; i=j \\
\sigma_{i i}=\frac{\tau_{i i}+S_{i}{ }^{2}-\mathrm{S}_{\mathrm{i}}}{S_{i}{ }^{2}} i=E, N, K
\end{gathered}
$$

and price elasticities are given by:

$$
\begin{aligned}
& E_{i j}=S_{j} \sigma_{i j} \\
& E_{i i}=S_{i} \sigma_{i i}
\end{aligned}
$$

Before estimating the above model a similar translog sub-module in energy components has been estimated. More specifically the translog cost function corresponding to various energy components may be written as follows:

$$
\ln P_{E}=\ln \beta_{o}+\sum_{i} \beta_{i} \ln P_{E i}+\sum_{i} \sum_{j} \beta_{i j} \ln P_{E i} \ln P_{E j}
$$

where $P_{E}$ is the aggregate price index of energy but can also be viewed as the cost per unit of energy to the optimizing agent.

The cost minimizing input demand functions corresponding to Equation (5), after imposing homogeneity, symmetry and adding-up restrictions are given by:

$$
S_{E i}=\beta_{i}+\sum_{j} \beta_{i j} \ln P_{E j}
$$

First the sub-module consisting of Equations (5) and (6) has been estimated and hence interfuel substitution and price elasticities are estimated. In addition, the parameter estimates are substituted in Equation (5) to obtain an aggregate price index for energy which in turn has been used as an instrument variable in the estimation of the aggregate production function. More specifically $P_{E}$ in Equations (1) and (2) has been replaced by the instrument variable thus obtained and then these two equations are estimated.

Annual time series data for the period 1960-80 have been used. All data on quantities and prices, except for energy have been taken from Naqui et al [9]. The data on energy components, both quantities and prices have been taken from the Energy Year Book. ${ }^{1}$ All energy quantities have been converted into Btus.

\section{Results}

Zellner's iterative estimation procedure has been used. The invariance of the estimates of the parameters has

\footnotetext{
${ }^{1}$ It includes only commercially purchased energy and therefore does not account for energy (especially electricity) which is self-generated by industry. However. this component has become relatively more significant in recent years. The data on gas excludes the use of gas as a feedback in fertilizers.
}

been ensured in both the energy sub-module as well as in the aggregate model by cstimating each of the models three times, dropping one share equation at a time.

The parameter estimates of the energy sub-module are presented in Table 1. Eleven out of twelve parameters are significant at the $1 \%$ level. The own- and cross-price elasticities are presented in Table 2. Ownprice elasticities for electricity and oil take correct signs

\begin{tabular}{|c|c|}
\hline$\beta_{E}$ & $\begin{array}{l}0.3386 \\
(5.55)\end{array}$ \\
\hline$\beta_{T E}$ & $\begin{array}{l}0.00627 \\
(2.50)\end{array}$ \\
\hline$\beta_{G}$ & $\begin{array}{l}0.2924 \\
(8.49)\end{array}$ \\
\hline$\beta_{T G}$ & $\begin{array}{l}0.00939 \\
(8.34)\end{array}$ \\
\hline$\beta_{O}$ & $\begin{array}{c}0.3688 \\
(7.91)\end{array}$ \\
\hline$\beta_{T O}$ & $\begin{array}{l}-0.01616 \\
(-6.76)\end{array}$ \\
\hline$\beta_{E E}$ & $\begin{array}{c}0.1745 \\
(4.13)\end{array}$ \\
\hline$\beta_{G G}$ & $\begin{array}{c}0.1894 \\
(9.01)\end{array}$ \\
\hline$\beta_{O O}$ & $\begin{array}{c}0.0942 \\
(2.99)\end{array}$ \\
\hline$\beta_{E G}$ & $\begin{array}{l}-0.1348 \\
(-5.87)\end{array}$ \\
\hline$\beta_{E O}$ & $\begin{array}{l}-0.0396 \\
(-1.21)\end{array}$ \\
\hline$\beta_{G O}$ & $\begin{array}{l}-0.0546 \\
(-4.49)\end{array}$ \\
\hline$£$ & 101.455 \\
\hline
\end{tabular}
and are significant at the $5 \%$ level. The price elasticity for gas is positive, but insignificant, at the $5 \%$ level. Cross-price elasticity between electricity and gas is negative but insignificant. This is also the case with the

Table 1. Parameter estimates of the share equations (inter-fuel).

Note: $E=$ electricity, $G=$ gas and $O=$ oil.

Table 2. Inter-fuel price elasticities

\begin{tabular}{lc}
\hline$\tilde{n}_{E E}$ & -0.1144 \\
$\tilde{n}_{G G}$ & $(-1.59)$ \\
$\tilde{n}_{O O}$ & +0.1152 \\
& $(1.14)$ \\
$\tilde{n}_{E G}$ & -0.3304 \\
& $(-2.11)$ \\
$\tilde{n}_{E O}$ & -0.01963 \\
$\tilde{n}_{G O}$ & $(-0.503)$ \\
& 0.134 \\
$\tilde{n}_{G E}$ & $(2.389)$ \\
$\tilde{n}_{O E}$ & -0.0598 \\
& $(-1.02)$ \\
$\tilde{n}_{O G}$ & -0.0554 \\
& $(-0.503)$ \\
& 0.393 \\
& $(2.40)$ \\
& -0.062 \\
\end{tabular}


Table 3. Parameter estimates with instrument for $P_{E}\left(P_{E}\right)$.

\begin{tabular}{lccc}
\hline$\alpha_{O}$ & -1.405 & $\tau_{N K}$ & -0.0747 \\
& $(-0.311)$ & - & $(-2.22)$ \\
$\alpha_{u}$ & 1.12 & $\tau_{N E}$ & -0.00532 \\
& $(0.966)$ & & $(-0.706)$ \\
$\alpha_{n}$ & 0.279 & $\tau_{K E}$ & -0.0595 \\
& $(1.123)$ & & $(-12.49)$ \\
$\alpha_{K}$ & 0.7544 & $\tau_{q n}$ & -0.07789 \\
& $(3.32)$ & & $(-2.24)$ \\
$\alpha_{e}$ & -0.0339 & $\tau_{q e}$ & $-0.0359)$ \\
& $(-0.897)$ & & $(-6.61)$ \\
$\tau_{N N}$ & 0.08009 & $\tau_{q k}$ & 0.1138 \\
& $(2.14)$ & & $(3.62)$ \\
$\tau_{K K}$ & 0.1342 & $\alpha t$ & -0.0989 \\
& $(4.356)$ & & $(-4.13)$ \\
$\tau_{E E}$ & 0.0647 & $\tau t_{\mathrm{n}}$ & 0.009164 \\
& $(9.69)$ & & $(3.56)$ \\
$\tau t_{\mathrm{K}}$ & -0.0138 & $\tau t_{\mathrm{e}}$ & 0.00464 \\
& $(-5.89)$ & & $(10.55)$ \\
\hline
\end{tabular}

Table 4. Price and substitution elasticitics between factor inputs, using $P$ as instrument.

\begin{tabular}{lcc}
\hline & Elasticity & t-ratio \\
$\sigma_{N N}$ & -3.3653 & -4.5539 \\
$\sigma_{E E}$ & -0.14096 & -1.7919 \\
$\sigma_{K K}$ & -0.24978 & -3.6724 \\
$\sigma_{N E}$ & 0.39729 & 4.3890 \\
$\sigma_{E N}$ & 0.071998 & 4.4679 \\
$\sigma_{K E}$ & -0.047005 & -4.3471 \\
$\sigma_{E K}$ & -0.25632 & -4.3475 \\
$\sigma_{N K}$ & 0.29330 & 4.0557 \\
$\sigma_{K N}$ & 0.29679 & 3.9816 \\
$\mathrm{~S}_{N E}$ & 0.86190 & 4.416 \\
$\mathrm{~S}_{K E}$ & -0.5627 & -4.306 \\
$\mathrm{~S}_{N K}$ & 0.64387 & 4.0218 \\
\hline
\end{tabular}

Note: $E=$ energy, $N=$ labour, $K=$ capital.

cross-price elasticity between oil and gas. Electricity and oil are substitutes. However, the degree of substitution is low. Generally, it seems that there has been little interfuel substitution in the manufacturing sector of Pakistan.

In the second stage the aggregate model consisting of Equations (1) and (2) has been estimated using $P_{e}$ obtained from Equation (5) as instrument for $P_{E}$. The parameter estimates are presented in Table 3.

Thirteen out of eighteen coefficients are significant at the 5\% level. The corresponding price and substitution elasticities are presented in Table 4. All the own-price elasticities take correct signs and are significant at the

\footnotetext{
${ }^{2}$ There had been some rationing policies along with pricing policies, especially in relation to electricity. This may partly explain the rclatively inelastic behaviour of energy.

${ }^{3}$ Griffin has discussed the plausibility of various explanations in more detail [5].
}

$5 \%$ level. However, the degree of price responsiveness is not high. Particularly the price elasticity of energy demand is quite low. ${ }^{2}$ The cross-price elasticities between employment and energy are positive and significant. The degree of substitution as depicted by the corresponding substitution elasticity is sizable. This result is similar to earlier such studies for other countries (Apte [1] and Vashist [11]).

The more interesting result is the negative cross-price elasticity between capital and energy. The corresponding substitution elasticity is also negative and significant at the 5\% level. It implies that capital and energy are complements. There has long been controversy about energy-capital complimentarity. Most of the studies which used annual time series data have found energy and capital to be complements (Berndt and Wood [2]. Fuss [4], Hudson and Jorgenson [7] and Magnus [8]). However, some inter-country and cross-sectional studies report the two inputs as substitutes (Griffin and Gregory [6]), one of the explanations, which seems more plausible in our case, relates to the time horizon for which the production relation is estimated. ${ }^{3}$ In the short run, if other inputs can be substituted against the capital-energy aggregate, capital and energy may be complements. In our case also the period covered may not be long enough to let the energy-capital adjustments work out fully.

\section{Conclusion}

The purpose of this study was to estimate the extent of interfuel substitution as well as substitution between energy and non-energy inputs in the large-scale manufacturing sector of Pakistan. The results do not provide evidence for significant interfuel substitution. As regards the substitution between energy and other inputs, our results indicate that energy and labour are substitutes whereas energy and capital are complements.

\section{References}

1 P. C. Apte, 'Substitution among energy and non-energy inputs in selected Indian manufacturing industries: an econometric analysis', Indian Economic Journal, Vol 31 , No 2, 1983, pp 71-90.

2 E. R. Berndt and D. O. Wood, 'Technology, prices and the derived demand for energy', Review of Economics and Statistics, Vol 57, No 3, August 1975, pp 259-268.

3 E. R. Berndt and D. O. Wood, Technical Change, Tax Policy and the Derived Demand for Energy, mimeo, University of British Columbia.

4 M. Fuss, "The demand for energy in Canadian manufacturing: an example of the estimation of production structures with many inputs', Journal of Econometrics, Vol 5, January 1977, pp 89-116. 
5 J. M. Griffin, 'The energy-capital complementarity controversy: a progress report on reconciliation attempts', in E. R. Berndt and B. C. Field, eds, Modelling and Measuring National Resource Substitution, MIT Press, 1981.

6 J. M. Griffin and P. R. Gregory, 'An intercountry translog model of energy substitution responses', American Economic Review, Vol 66, December 1976, pp 845-857.

7 E. A. Hudson and D. W. Jorgenson, 'US energy policy and economic growth, 1975-2000', The Bell Journal of Economics and Management Science, Vol 5, No2, Autumn 1974.
8 J. R. Magnus, 'Substitution between energy and nonenergy inputs in the Netherlands: 1950-1976', International Economic Review, Vol 20, June 1979, pp 465-484.

9 S. N. A. Naqui, A. H. Khan, N. M. Khilji and A. M. Ahmad, The PIDE Macro-econometric Model, PIDE, PB1091, Islamabad.

10 H. A. Pasha, A. Ghaus and S. Malik, 'The economic cost of power outages in the industrial sector of Pakistan', Energy Economics, Vol 11, No 4, 1989, pp 30l-318.

11 D. C. Vashist, 'Substitution possibilities and price sensitivity of energy demand in Indian manufacturing', Indian Economic Journal, Vol 32, No 2, 1984, pp 84-97. 